\title{
HOW STRUCTURE INFLUENCE RELATIONAL CAPITAL: THE IMPACT OF NETWORK COMMUNICATION IN CENTRALIZED STRUCTURE
}

\author{
LOKHMAN HAKIM BIN OSMAN ${ }^{1}$, AHMAD RAFLIS CHE OMAR $^{2}$, \\ AzHAR Ahmad ${ }^{3,}$ AbDullah Sanusi Othman ${ }^{4}$ \\ 1,2,3,4 School of Management, Faculty of Economy and Management, \\ Universiti Kebangsaan Malaysia \\ lokhman@ukm.edu.my
}

\begin{abstract}
This research looks into the different effects of firms' network structural positions in an upstream supply network upon the firms' level of relational capital outcomes. Previous research has largely focus on the context of decentralized network structure. However, the supply network is a centralized network because of the existence of the focal firm. The existence of the focal firm may influence the impact of relational capital outcomes Objective: To determine the type of network structural postions required to obtain reasonable relational capital outcome in upstream supply network Results: Network structural positions i.e. degree centrality contributed to firms level of relational capital trust. Conclusion: Firms, embedded in upstream supply network benefits differently in terms of relational capital through different degree of embeddedness. Firms' resources should be re-aligned to match the benefits with the different network structural positions.

Keywords: Supply Chain Management; Network Studies; Inter-Organizational Relations; Social Capital; Supply Chain Complexity
\end{abstract}

1. Introduction. The last decades have seen an increase in managerial concern regarding the complexity of the supply chain, more specifically the upstream supply network. The upstream supply network refers to the firms that reside in the upstream flow of the supply network. The upstream supply network has become more complex due to the increase interactions and interrelations among the suppliers' firms as well as the number of the firms. These firms which are the suppliers of materials and services to the focal firms are connected or involved with each other directly or indirectly through the supply of materials to the focal firms or manufacturer.

One of the main strategies of managing these inherent complexities that is often adopted by supply chain managers includes reductionist approach. The traditional reductionist arguments state that firms opted for the removal from the complex upstream supply chain of partners who are not meeting the performance requirements of the supply chain in an attempt to manage the complexity arising from extensive inter-firm relationships (Choi and Kim, 2008). These strategies may prove to be effective in the short term, but may negatively impact the focal firms in the long run. These negative effects may emerge as firms' involvement in a network of inter-firm relation, creates an important element of intangible capital, which is the relational social capital. This involvement among the firms in the upstream supply network is essentially the firm embeddedness in the upstream supply network structure. However, recent arguments suggest that simply removing these underperforming firms may not be the best way, as firms may remove partners who are resourceful or more influential, but these characteristics are not visible through good accounting measures. 
In this vein, Cockburn and Henderson (1998) in addition to Putnam $(1993 ; 2000)$ posited that approaches that value and appreciate these complex inter-firm relations may be better alternatives. This is because, firms have been found to benefit through embeddedness with other firms in a network structure.

Network embeddedness constitutes an important element that Putnam (1992) identifies as being the relational capital (Cousins et al. 2001). Cousins et al. (2006) stated that relational capital was the configuration of relationships within the network structure, as well as with the broader network structure of the firm. It has been documented that the level of embeddedness increases relational capital such as trust and motivation from the interactions (Cousins et al., 2006). More specifically, organizational researchers have confirmed that organizational involvement in a decentralized network structure impacts upon organizational relational capital outcomes such as the level of trust (Gulati and Gargiulo, 1999; Podolny and Page, 1998). Thus, a firm's embeddedness in the network structure may produce relational capital such as trust that may then have the potential to generate other benefits such as reduced costs and greater flexibility (Reagans, Zuckerman and McEvily, 2004). Nevertheless, in the decentralized and horizontal communication structure of networks causes opportunistic acts to become an imminent threat. Opportunism may emerge when parties in the network relationship have issues of goal incongruence. In addition, connectivity may have its costs too, as a firm may lose some control of its operations and administrations. Naturally, in a supply network context, to guard against the instability of the network structure and threat of opportunism, while at the same time acquiring high levels of integration among firms in the supply network structure, stakeholders in the network structure often introduce a focal or central firm to administer and manage the activities in the network

structure (Huang, 2007). This is the case that we are investigating.

The upstream supply network is essentially a centralized network structure. It is a centralized structure through the existence of the focal firm that monitors and administers transactions in the upstream supply chain for the production of the finished goods and services. This centralized coordination often involves a focal firm or manufacturer, typically operating in the center of the transformation process (Choi and Krause, 2006). Since relational capital outcomes emerge through interactions in a free flow, decentralized, network structure (Gulati and Gargiulo, 1999; Podolny and Page, 1998), application of the integrated network to the issues of centralized upstream supply network complexity may require deeper understanding of the impact of the centralized network structure. This research raised this concern following the argument of Putnam (1992) which posited that relational capital emerged largely in a decentralized network structure.This is because; a centralized coordination such as the focal firm in the upstream supply network may introduce effects unknown, or remove potential benefits to the firms in the upstream supply network. For example, since the central coordinator (i.e. the focal firm), is often the most powerful firm in the supply base having arms-length control that monitors actions of the network member, it is also a profit-driven entity with the most investment in the supply network. Occasionally albeit unintended, a Machiavellian portrayal may affect the level of relational capital among the firms in the centralized network structure. In addition, the centralized nature of network governance has been found to reduce the horizontal connection which is prominent for the creation of relational capital in a network structure (Poppo and Zenger, 2002). Since these horizontal connections are significant for generating the relational capital posited by Putnam (1992), a key question would be: will firm involvement or embeddedness in the centralized upstream supply network produce the same relational capital outcomes?

2. Literature Review ". ... firms are no longer structured like a medieval kingdom, walled off and protected from hostile outside forces...but...involved in an intricate lattice work of collaborative ventures with other firms, most of whom are ostensibly competitors" (Powell, 2003)

Powell's (2003, p. 113) statement described the overall transition of organization form over the years as follows: The adoption of network firms in the upstream supply network structure relates to the assertion of network forms of organization in an inter-organizational or inter-firm relationship as conducted by an organizational study researcher. Integrated network refers to the notable structure of the inter-firm relationship. Globalization has made the study of inter-firm relations increasingly important, as the resources needed to undertake the task of organizational management have grown in scale. Hence, this limits the potential of independent action by any single organization (Kauffman, 1993). It is believed that a 
holistic understanding of the inter-firm relationship would catapult organizations into providing better service as well as cost reduction (Faems, Van Looy and Debackere, 2005; Krauss, Mueller and Luke, 2004; Lawson et al., 2009; Stuart, Hoang and Hybels, 1999). This situation arises because a network, argued Powell (1990), facilitates the exchange of efficient and reliable information. This is due to the relational capital developed through the firms' level of embeddedness in the network structure.

Granovetter (1985) advanced the concept of embeddedness as an effort by which to explain economic behavior of an organization. According to Granovetter (1985), embeddedness refers to the level of involvement of a firm in the network of inter-relations. A firm's levels of involvement have an impact upon its actions or behavior in the network. Granovetter (1985) posited that transactions between actors in a network are embedded in a social context economic decisions and outcomes are affected not only by the actor's isolated relations with other individuals or firms in the network but also by the structure of the overall network of relations within which the actor resides. Economic behaviors are embedded in the network of relations that provide the context for economic processes (Granovetter, 1985). As every behavior materializes through some form of outcome, almost all economic processes are presumed to be embedded in the networks of relations. Thus organizational performance is influenced by the pattern of embeddeness of the organization in the network. Since in the upstream supply network, firm embeddedness relate to the degree of the interaction that a firm may has with other firms in the network which are a direct reflection of the firm degree of inter connectivity with others in a network. Hence, one may conclude that organization performance in the supply network may also be influenced by the organization embeddedness pattern such as its centrality and connection (Scott, 1998) with other organizations in the supply network (Mueller, 2000). This is because, structurally, supply network is virtually formed by the connectivity or links between firms where the integration progressively forms the ultimate structure, which is the supply network itself. The relationship is also known in the literature as the buyer-supplier relationship (Beamon, 1999). According to Choi and Kim (2010), a buyer-supplier relationship represents a dyad, or two nodes and one link, in network terms. Each node can be conceptualized as an actor performing activities for generating value Choi (2008). The firms need resources from its supplier organization, and the supplier needs contracts and payments from the buyer. On top of that the firms also interact with each other to share information regarding market opportunities and new threats (Choi, 2008). As a consequence, these phenomena create a link and form a dyad or a buyer-supplier relationship. Because a firm in the supply network often has links to other firms, the firm is then impliedly linked to the new indirectly connected organizations. Similarly, with the supplier organization, this will also bring to the dyad their links with other organizations either directly or indirectly (Lamming et al., 2000). Conclusively, a buyer-supplier relationship is not only a dyad. It is also part of a network that has come to bear on individual nodes to the relationship through each other's extended business relationships. This form of inter-firm relations or connectivity created the complexity in the supply network structure.

Although there has been increase number of research regarding firms embeddedness in network, however, the literature is silent about the relationship between organizational embeddedness and organizational social capital in a centrally governed supply network that is a network governs by a strong focal organization which enforces and monitors the supply and demand of materials by other sub organizations in the network. Network scholars have found a strong relationship between organizational embeddednes in network structure and organizational social capital in a decentralized network form of organization (Wasserman and Galaskiewicz, 1994, Ter Wal and Boschma, 2009, Chang, 2003a, McEvily and Zaheer, 1999, Ahuja, 2000, Anderson et al., 1994, Provan et al., 2007, Galaskiewicz and Marsden, 1978, Johnson and Mareva, 2002, Haibin, 2004, Breschi and Lissoni, 2005, Hite et al., 2005).

In this research, although no doubt organizational social capital emerged in network forms of organizations, we argue that the presence of a central actor of or dominant power such as the focal organization in a supply network, may change the pattern of inter connectivity and ties among organizations in the network hence the impact to the organizational social performance. At the minimum, the flow of information may have to go through the central actors before it can be disseminated to other actors in the network. Furthermore, the formal power of the central organization may add new perspectives to the informal, social control mechanism operating in the network. 
2.Hypothesis. Extensive interactions generate trust among firms. For example, Uzzi (1997) found that, in order to obtain information regarding a potential partner before collaboration activities can be carried out; firms resort to trusted firms for information. The trust between the firms, argued (Uzzi (1997) is the result of multiple exchanges in the past. In the same vein, Gulati (1995) highlighted that years of inter-firm relationships generate trust among them. In addition to that, Gulati and Gargiulo (1999) found that negative gossip by third parties about another party's uncooperative behaviour significantly reduces the likelihood of direct relations; whereas positive gossip strengthens the likelihood of direct relations among firms in the network. What this literature shows is that, in a network relationship, a firm will sometimes refer to its partner's previous experience and information with potential partners before agreeing to short-term or longterm business commitments. Extensive interactions are a catalyst for trust in networks of inter-firm relations. Similarly, Eccles (1981) found that extensive interactions among a network of homebuilder firms also create trust among network members. The authors found that exchanges of information among the contractors regarding materials prices create stronger inter-firm relationships and thereby facilitate the creation of trust.

Trust also materializes in the long run through the contract relations among firms. For example, Brown and Troutt (2004) found that trust emerged through extensive contracts and social relations between government organizations and non-profit organizations. McEvily, Perrone and Zaheer (2003) found that an important structural condition in a network of inter-firm relationship is trust. A firm that loses the trust of its network members may see that some of its ties are removed and the firm itself is pushed into the periphery from the core network position. Consequently, this will create a new firm that will take the central figure and become the core firm in the inter-firm network. Thus, the literature indicates that firms in a network having an extensive relationship with other firms in the network may be perceived as trustworthy by others. Since extensive relationships in network analysis can be pictured based on the level of firms' coreness in the network structure, this thesis hypothesizes that:

Hypothesis: Firms' embeddedness following their centrality position in the upstream supply network through different inter firm relations impact the level of trust that the firms may acquire from other network members.

3. Methodology. Align with the objectives of this study; the design and methodology of are based on the theoretical and analytical framework of the Social Network Analysis (SNA). For this study, an upstream supply network of a small maritime industry seemed to be an ideal setting. A supply network in the maritime industry is a material-intensive enterprise. Much of the activities and activities are highly dynamics and are widely dispersed throughout the network. Materials and information flow are transferred through interactions among different firms. Because firms in supply network operate in an environment of high degree of complexity (Bozarth et al., 2009) and uncertainty (Wilding, 1998a), these firms seek an edge through connections or interactions with the members of the network.

Lambert and Cooper (2000) stated that the key to these issues is the on-going relationship with the other partners. They stressed about the importance of investigating the relationships that suppliers and customers have. Johnston et al. (2004) suggested that on-going relationship among member of the supply network increases efficiency and effectiveness of the supply network. The research site of this study is located in the country Malaysia. The researcher profiles different supply networks critically to determine the most suitable network for study. One of the networks, here labelled as APMMHQ-1 supply network, was found to be the appropriate site for this exploration. The top level managements were approached for possible participations in the study. After several communication about the goal of this study and the potentials benefits for the APMMHQ-1 supply network, positive commitments were received from the top managements to participate and granting participations to this study. In network studies, all the actors that are located within the naturally occurring boundaries are included for analysis. Consequently, network studies do not use samples as in the conventional sense, rather, it seek to include all of the actors in some population or populations (Hanneman and Riddle, 2005). Defining and locating the boundaries of a network is utmost important in a network study. To identify and define the target population within the APMMHQ-1 upstream supply network for RHIB, for this study, the author combines the realist and the nominalist approach.

A survey instrument was used to collect majority of the information needed for this study. Surveys and 
questionnaire are traditional tools to help network researchers to obtain data on inter-organizational relationships (Wasserman and Faust, 1994). Leading network researcher such as Galaskiewicz and Marsden (1978), Knoke and Kuklinski (1982), Burt (2004), and Borgatti and Li (2009a) established the credibility of this technique for the collection of network data on inter-organizational transactions such as information transfer, resource transfer and joint activities. Survey is suitable for this type of study because it allows the researcher to tap into the participants' subjective perceptions of interactions rather than objective measure of interactions, which many situations are hard to get access to for confidentiality reasons (Diani, 2002). The survey instrument used in this study followed standard survey design features such as asking general information questions at the beginning, followed by more specific questions, and lastly the most probing questions at the end. The survey questionnaire consisted of closed ended questions and open ended questions. In general the questionnaire were framed following the standard of Choi and Hong (2002), Provan and Milward (1995), Stone (2001), Corteville and Sun (2009) and Cross and Parker (2004).

For data analysis, the analysis was divided according to the type of analysis technique applied. First, the researcher performed exploratory social network analysis (visual analysis) of buyer-supplier organizations network by exploring the network maps and the network structural measures. For this purpose, this research adopted a spring-embedding visualization method in the UCINET program whereby a network layout is computed using force directed algorithm. More specifically, the algorithm place nodes based on node repulsion and equal edge length bias. When so configured, the placement of nodes in the sociogram is based on forcing the nodes apart and tending to select placements that lead to equal edge lengths (i.e., equal length lines between nodes). This particular layout has the advantage of detecting network centrality patterning (Polites and Watson, 2008). For these routines, this research applied the network imaging software within the UCINET (Borgatti et al., 2002) i.e. the NetDraw, which is equipped with sophisticated visualization techniques. Visual representation of supply networks can provide useful direction for researchers, and starting point to developed subsequent quantitative analyses (Choi and Hong, 2002b).

Secondly, the researcher tested the research hypotheses using innovative statistical network modeling known as the Exponential Random Graph Modeling (ERGM, or p* model; Robins et al., 2007b). Robins, Elliott et al. (2001) suggested that in social network analysis, the network structure need to be searched not assume from previous other related literature.

In general, the exponential random graph models (ERGM) have the following form:

$\left.P_{r}(Y=y), 1 / k\right) \exp \left(\sum n A(g) A(y)\right)$

Where:

(i) The summation is over all configurations A;

(ii) $\eta \mathrm{A}$ is the parameter corresponding to the configuration $\mathrm{A}$ (and is nonzero only if all pairs of variables in A are assumed to be conditionally dependent)

(iii) $\mathrm{gA}(\mathrm{y})$ is the network statistic corresponding to configuration $\mathrm{A} ; \mathrm{gA}(\mathrm{y})=1$ if the configuration is observed in the network $\mathrm{y}$, and is 0 otherwise

All ERGM models are of the form of equation (1), which describes a general probability distribution of graphs on $\mathrm{n}$ nodes. The probability of observing any particular graph $\mathrm{y}$ in this distribution is given by the equation, and this probability is dependent both on the statistics $\mathrm{gA}(\mathrm{y})$ in the network $\mathrm{y}$ and on the various non-zero parameters $\eta \mathrm{A}$ for all configurations $\mathrm{A}$ in the model. Consequently, different network analysis routines were applied to explore patterns of connectivity among the buyer-supplier organizations that are embedded in the MMEA supply network and examine the structural characteristics of these entities. These analyses were performed using the software package UCINET (Borgatti et al., 2002).

\section{Findings and Discussion.}


4.1 Exploratory Network Analysis: Visual Analysis of Social Network Trust Network Map and Degree Centrality. It can be seen immediately from Figure 1 that there is several sub-groups or cliques of trust relationship in the network structure. In addition in the almost all sub-groups or cliques, there exists one firm that have high trust attribute compare to other nodes. Furthermore, nodes that are periphery in the network are mostly low in their trust score. This network map implies that nodes that are embedded in the core position may experience high level of trust while nodes on the periphery have mostly low trust level. Together, the positioning of the nodes of the trust network indicates the tendency towards a degree based core-periphery structure. Borgatti and Everett (2000) stated that the core periphery structures imply the existence of two distinct regions in the network, i.e. one that include dense and cohesive subsets of nodes, and another where connections are looser and sparse. Borgatti and Everett (2000) posited that these particular structure may form in two ways, i.e. one as a result of high centralization process, indicated by the presence of hubs and spokes nodes, for example when prominent firms attracts most of the other firms, and another, due to high triangulation, which suggest the presence of large number of overlapping cliques.

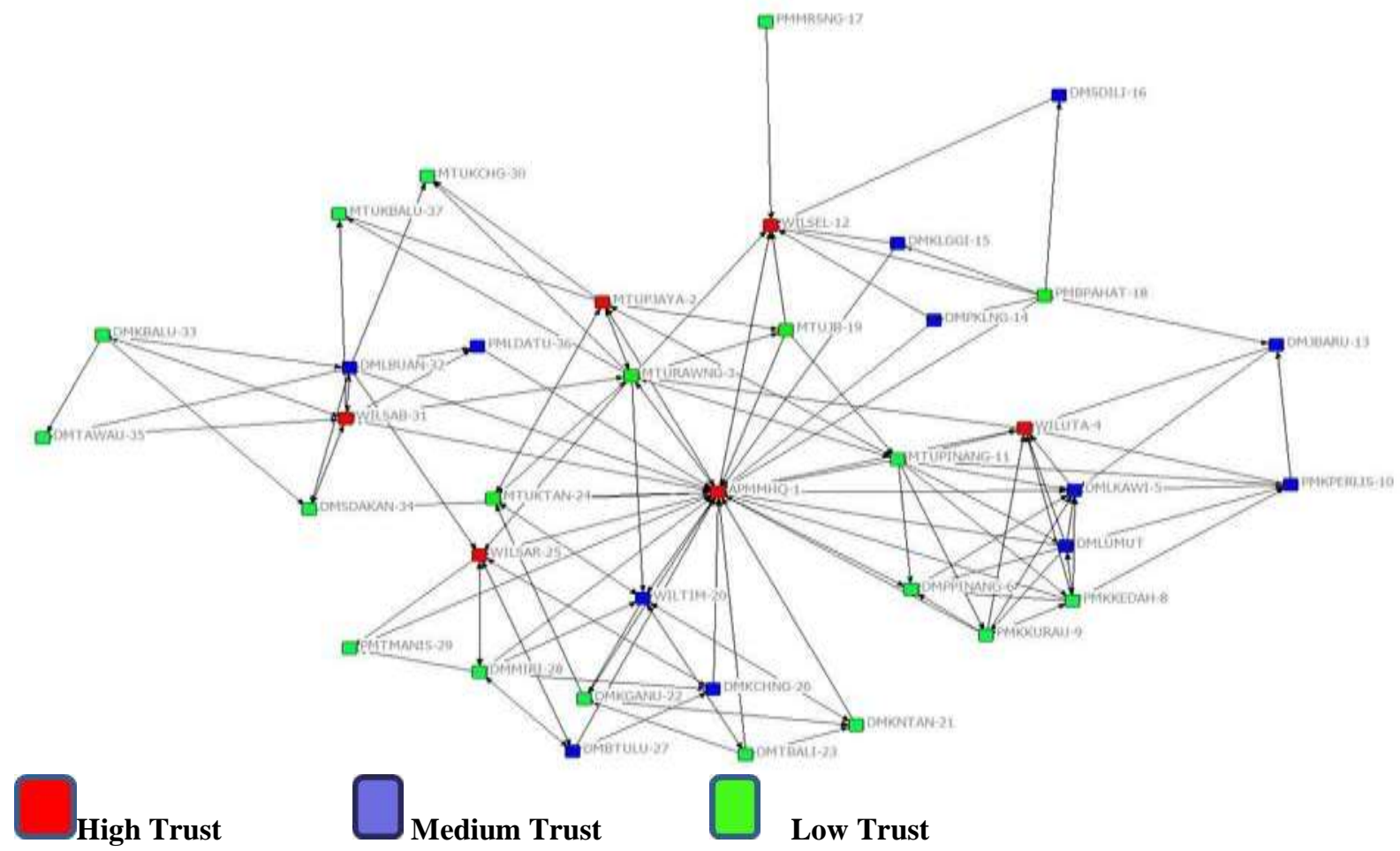

Figure 1 Trust network with color on the nodes representing high and low trust score

4.2 ERGM Analysis of Trust Network and Embeddedness Based on Degree Centrality. To test for the effects of nodes embeddedness attribute in a more systematic way, this study performed a series of ERGM analysis, which allow the researcher to statistically determining the effects of organizations measures of network embeddedness upon trust network (Snijders et al., 2006, Robins et al., 2009). For the ERGM analysis this study adopted Shumate and Palazzolo (2010) Pure Structural Effects and Pure Attribute Effects model analysis. In the initial analysis, the researcher conducted the Pure Structural Parameter Effects model ERGM analysis to determine the relevant structural formation of the trust network. Following this, the researcher conducted another ERGM analysis with the buyer-supplier organizations measurs of network embeddedness or node attributes included into the model. This model is called the Pure Attribute Based Network Effect model. The outcome of this model will enable the researcher to see the impact of the attribute upon the ties structural formation propensity inside the relevant network and more importantly upon the node attribute parameters. The relevant node attribute parameter to test for these effects is the the Sum of Continuous Attribute and supplemented by the Difference of Continuous Attribute parameters. Using these parameters the researcher will be able to tell the individual effects of the attributes upon the buyer-supplier 
organizations in the network. Following Robins et al.(2007a), the researcher analyse the MLE (Maximum Likelihood Estimate), and the standard error. The parameter is significant when absolute value of estimates exceed twice the standard error outcomes of each models. The sign of the MLE ("+" or "_") provides an indication of whether the particular network structure occurs more or less likely than predicted by chance. For a model to be considered well converged the parameters t-ratio must be less than 0.1 is absolute value. All of the parameters included in this study models are under the convergence threshold, indicating that the models fit the data well. In the following section this thesis discuss the analysis results of ERG model for trust network and embeddedness attributes measured based on degree centrality in the formal contract tie, information sharing tie, referral made tie, and referral received tie.

4.2.1 MMEA Trust Network with Organization Network Embeddedness Degree Centrality (ONEDC). In this section, the researcher discuss the ERGM analysis results involving embeddedness of firms measured based on the ONEDC across four supply ties. For reason of constraints place on this study report, the researcher will only discuss the Pure Structural Effects model results followed by the model effects of the embeddedness attributed as represented by the Sum of Continuous Attribute and the Difference of Continuous Attribute parameter of each supply ties. The parameter estimates (MLE), and standard error are presented in Table 1.

Table1 ERGM Results

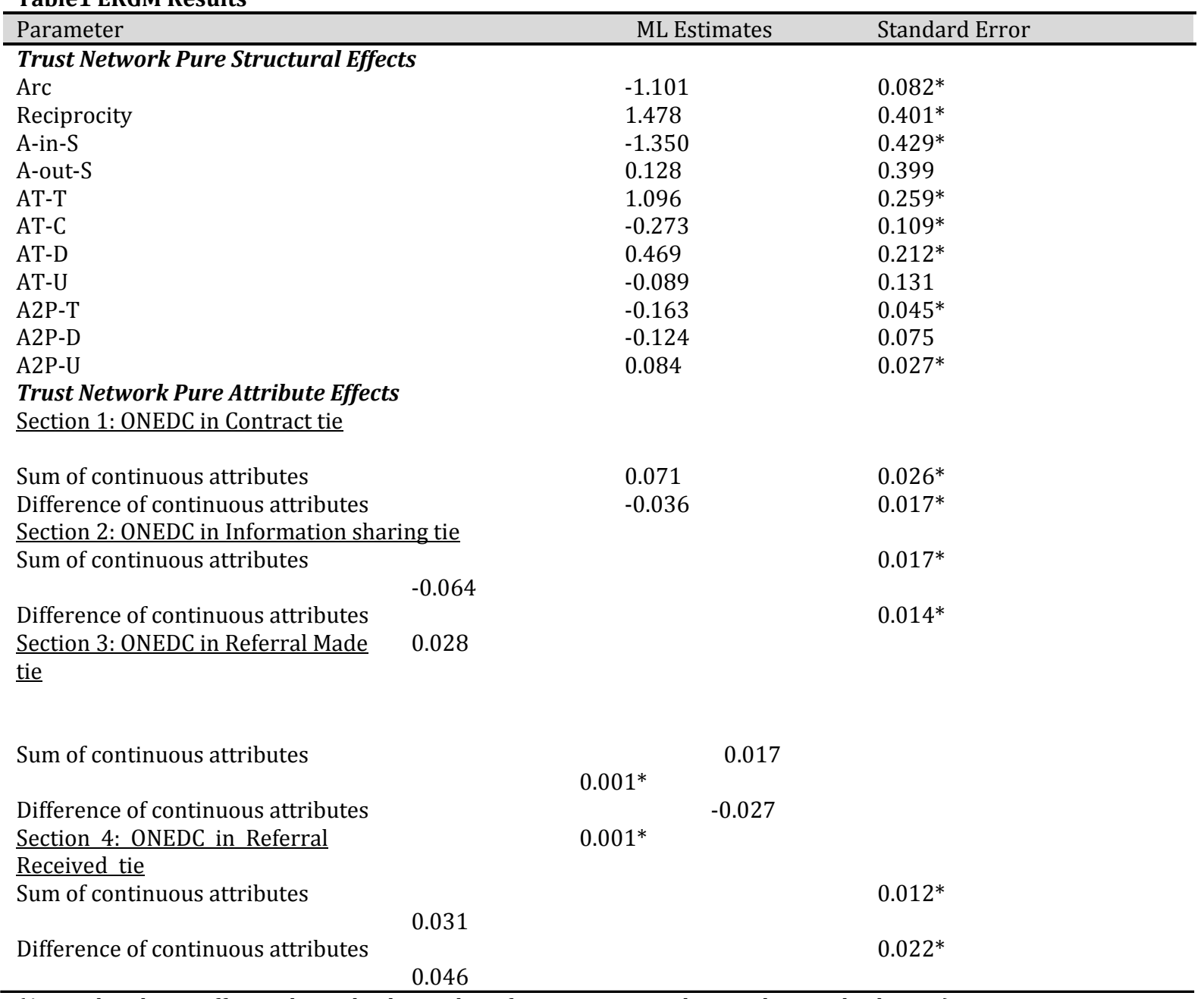

(Asterisk indicate effects where absolute value of estimates exceed twice the standard error)

In Table 1, to obtain a converged Pure Structural Effects model for trust network, the structural parameters are included conditionally until the model is converged i.e. until the t-ratio of each relevant parameter is less than 0.1 . Consequently, the parameters that are included in the Pure Structural Effects model of the trust network are as 
follow: Reciprocity, A-in-S, A-out-S, AT-T, AT-D, AT-U, AT-C, A2P-T, A2P-U, and A2P-D. Structurally these parameters reflect certain form of ties structural formations in the trust network. These parameters reflect density (arc), reciprocation (reciprocity), degree based or centralization (A-in-S, A-out-S), and multiple transitivity (AT-T, AT-D, AT-U, AT-C, A2P-T, A2P-U, and A2P-D) (Robins et al., 2009, Wang et al., 2006b).

First, in the structural effects section, the Arc ML estimate is a significant and negative parameter, suggesting fewer trust relationships are expected it the MMEA supply system are observed than would have been expected by chance. In other words, firms of the MMEA supply network forge trust relationships to only a few of the potential other firms in the network. This phenomenon is expected as trust relationships are build overtime and relies on other endogenous variables such as size of the participating firms and the length of the relationships

(Jiang et al., 2011, Laaksonen et al., 2009, Doney and Cannon, 1997). Firms' size encompasses the firm's overall size and its market share position. Firms' size provides a signal to other firm its level of trustworthiness. Overall size and market share indicate that many other businesses trust this firm enough to do business with it. This suggests that the firms consistently deliver on its promises to others or it would not have been able to maintain its position in the industry.

Secondly, there is a significant and positive effect of reciprocity for trust network model. This indicate that firms are likely to nominate each other in trust relation i.e. if Organizations APMMHQ1 trust WILSEL4 there is also a high likelihood that WILSEL4 trust APMMHQ1 in return. Reciprocity is an important feature of many other social networks studies, and it is expected in trust relationships (Lusher, 2011, Lusher and Ackland, 2010, Lusher et al., 2010, Lusher et al., 2012, Bamber et al., 2010, Robins et al., 2012, Robins et al., 2009).

Third the model shows that the A-in-S parameter is significant but negative A-in-S parameter is an indication of the presence of highly nominated firms within the trust network. What can be taken from this parameter estimates is that in the trust network, controlling for other effects, although there is a significant parameter estimates for A-in-S, the negative MLE score indicate that it is unlikely that trust ties relationship will be forge based on the degree based structural formation. On top of the structural parameters, Table 1 also shows the effects of the continuous attributes upon the ties formation propensity between the embedded buyer-supplier organizations in the trust network in the attribute effects sections. The first section shows the results for ONEDC in contract tie. The Sum of Continuous Attributes is significant and positive. This shows that in the trust network, firms that have high ONEDC in contract tie forge trust ties with others with similar high embeddedness level and with low embeddedness level more frequently. Because the embeddedness score is related to the number of connections that firms has in the network, we could also relate this parameters to the location of these firms in the network structure. Structurally, we would find these firms to be located in the center of the network, as there are the nodes that has the most connections or ties to other nodes in the network. The Difference of Continuous Attribute is significant and negative suggest that the firms with differing level of embeddedness levels are less likely to forge ties together. What can be taken from the findings of the ERGM analysis outcome is that, ONEDC in contract tie influences the propensity for trust ties to be forged between the embedded firms. Thus, firms with high ONEDC may appear more trustworthy to the other network members.

In the second section, there is a negative and significant Sum of Continuous Attribute parameter indicating that firms with high ONEDC in the information sharing tie have low tendency to trust others with high or low ONEDC firms. A significant and positive Differences of Continuous Attribute shows that there is a strong tendency for firms in the observed network to forge ties or trust other network members when their ONEDC differences is small. When compare to the attribute effects in contract tie the Sum of Continuous Attribute effects is non-significant but positive and significant Difference of Continuous Attribute effects. The distinctions in the attribute effects may relate to the type of type of ties in question. A formal tie such as the contract tie is governed by terms and regulation. Such condition may lead to focal organizations becoming dominant in the network. For example, Toyota is the focal organization in the Toyota supply chain with few tier one organizations also considered focal, as they functions as the main supplier to the Toyota production facility. The flow of supplier between upstream suppliers to the focal suppliers and subsequently to the manufacturer itself is governed by agreed rules and regulations with the contracted organizations are bounded to the demands and needs of the ordering authority (i.e. focal organizations). This phenomenon may create a few focal organizations that become core nodes as indicated by the positive Sum of Continuous Attribute effects in the model. On the other hand, positive and significant Difference Continuous Attributes may be attributed to the informal nature of the information sharing tie whereby in such network, communication is not based and bounded by any official regulatory. 
The third section of trust network model in shows the attributes effects results for ONEDC in referral made tie. There is a significant and positive Sum of Continuous Attribute effects for the observed network indicating that firms with high ONEDC in the referral made tie tend to forge ties with others. The negative and significant Differences of Continuous Attribute shows that when the difference in their ONEDC is small there is low tendency for the firms of the observed network to forged trust ties with other firm.

Finally, the fourth section shows the result of attributes effects, ONEDC in referral received tie. The Sum of Continuous Attribute is found to be positive and significant. This is an indication that firms that possessed high ONEDC in referral received tie are likely to form ties with other with other network members. However, the positive and significant Difference of Continuous Attribute shows that trust relationship are more likely to be forge between network nodes when the difference in ONEDC in referral received tie are small.

5. Discussion. The exploratory analysis and the ERGM analysis revealed that there were significant, positive effects of firms' embeddedness based on centrality network positions and trust. For example, firms that are highly embedded in the information-sharing tie network, based on their degree centrality network structural position, have a high likelihood of being perceived as trustworthy by other network members. The results are similar in the referral made ties, and the referral received ties. This also indicates that, as firms are more embedded in the centralized upstream supply network based on the degree centrality network structural position, their level of trustworthiness as well improves. However, the Maximum Likelihood Estimate (MLE) is significant but negative when firms are highly embedded in the contract tie. What this means is that the more embedded a firm is in the upstream supply network based on the formal contract tie, the less is the likelihood that it will be perceived as trustworthy by other network members.

This suggests that the study hypothesis can be accepted. As a firm becomes more embedded in the upstream supply network structure, it will experience varying levels of relational capital depending on the type of activity that the firm is involved in. Thus, the more embedded a firm is in the supply network based on degree centrality network position, the more likelihood there is that the firm will be perceived as trustworthy by other firms embedded in a similar network structure. This implies that firms in an upstream supply network relationship trust the firms that occupy the central position in the supply network structure; alternatively, by definition, the firms that receive the most ties or connections from other firms.

Overall, it appears that firm embeddedness in the supply network structure contributes to the level of trust that one firm may receive from other network members. Moreover, the trustworthiness level that a firm receives from other colleagues may be helpful in the collaborative development of a new-product innovation or services. The level of trust can also influence the development and training of personnel; for example, to qualify them to deal with the partners' or customers' technology or system. The results of the parameter estimations are in line with the results of the trust network visual analysis (Figures 1). In this case, this study also found that, in the sociogram of trust network (Figures 1), firms that have a high level of embeddedness based on degree centrality are also the central firms in the trust network structure.

This finding is consistent with Uzzi (1997). Uzzi (1997) found that, in inter-firm relationships, active relational governance such as information-sharing is associated with trust. Further, it was found that firms resort to trusted firms in the network with whom they have dealt multiple times in the past to obtain information regarding a potential partner before collaboration activities can be carried out. More importantly, Zaheer et al., (1998) confirm that this leads to improved performance of inter-firm exchanges. An important implication of this is that these findings provide support that firm commitment into information-sharing activities enhances the perception of trust that the firm may receive from other network members. In addition, referral relationships are regarded as being a firm's high level of goodwill (Anderson, 1998). Referral relationships often involve sending human resources, or participating in programs to make certain of issues regarding clients or processes. As receiving referrals can be interpreted as receiving resources from other network members, others may regard the act of sending referrals to other firms as an act of goodwill. Consequently, firms that receive a high number of referrals will also be perceived as highly trustworthy by other firms in the network structure.

Thus, the findings of ERGM analysis for the hypothesis one lend support to the argument that firms are more embedded in the centralized upstream supply network. 
6. Conclusion and Recommendation. This study contributes to the extant body of relational capital, strategy and network literature. The relationship between inter-firm relations and relational capital has long been studied, but the empirical proof of a relationship in the context of a centralized network of relations was limited (Provan 2004). With the advancement of globalization, the upstream supply network has become more complex over the years. As the upstream supply network has become more complex, focal firms tend to monitor and administer the transactions and activities in the network, thereby creating a centralized network structure. Although Putnam (1990) argues that relational capital exists in a network structure of relations, the context of this research mainly focuses on the decentralized network structure. Choi (2008) made a number of propositions regarding several benefits that occur when firms are embedded in the centralized upstream supply network structure. This includes understanding which firms can be trusted and relied upon for resources. They warn the readers against dismissing partners in the centralized upstream supply network structure, based on accounting measures, when these firms are actually more trustworthy and reliable with regard to their resources and connections.

Relational capital exists in networks of inter-firm relations, such as in the centralized upstream supply network structure (Putnam, 1999). Being related to other firms in the upstream supply network is beneficial to firms subject to their holistic understanding of their embeddedness in the network structure. The inter-firm relations in the upstream supply network structure not only emerged from the formal administrative, but were also initiated through other webs of social exchanges. Among the firms that are embedded in the centralized upstream supply chain, some will gain more benefits compared to others as a result of firm embeddedness or involvement based on the respective network structural positions.

In this study, the researcher argues that the amount of benefits or the relational capital is related to the firms' level of embeddedness or involvement in the centralized upstream supply network. Specifically, the firm network centrality, clique overlapped and its multiplexity will impact upon firms' relational capital outcomes, such as trust, reputation and influence. Centrality, clique overlapped and multiplexity increase the transferability of interactions in a network structure and, consequently, the firms' relational capital outcomes.

In addition, this research has tested and confirmed the presence of relational capital outcomes in the context of a centralized network structure. This refers, at least, to the relational capital trust and relational capital influence in the context of a centralized upstream supply network structure. Organizational network researchers such as Putnam (1993) and Uzzi (1997) have examined cooperation in naturally-occurring horizontal network or decentralized network structures. Supply network, in its original form, is related to a managed organization network or centralized network, as initial formations are motivated by the needs of the focal firm to manage and administer the transactions of materials based on certain agreements. The difference between the naturally-occurring decentralized network structure and centralized network can be described as the bottom-up and top-down approach of cooperation. The top-down approach is facilitated by formal criteria. As this study's analysis indicates, cooperation is not totally antagonistic towards formal control. For instance, a high density index of the network structure of the informal information-sharing ties compared to the formal contract network indicates the high connectivity of firms in the information-sharing network rather than the contract network. The intensity of ties may represent the adaptability of cooperation in the centralized upstream supply network. These findings reaffirm the contention that even the formal, hierarchical institutions do not impede cooperation activities between the firms in the network and consequently, the creation of relational capital (Ostrom and Walker, 2000).

In other words, this study's finding suggests that stocks of relational capital do exist in the context of a centralized network structure, even though the hierarchical network has been considered as an impediment to growth.

In conclusion, by considering the overall implications of our study, we may conclude that complexity is not all bad. Managers need to consider their firm's existing embeddedness in order to exploit the competitive advantage of supply network inter-organizational relationships. Firms that fail to understand the underpinnings of these relationships stand to face more difficulties within the network itself. For this reason managers that intend to obtain competitive advantage from the network must engage with other partners more effectively. No doubt, some firms are at an adequate standing, while others are struggling in some areas. The framework of this study can be applied by managers who are committed in engaging other network members. 


\section{REFERENCES}

[1] Borgatti, S. P., \& Li, X. (2009). On social network analysis in a supply chain context*. Journal of Supply Chain Management, 45(2), 5-22.

[2] Borgatti, S. P., \& Molina, J. L. (2003). Ethical and strategic issues in organizational social network analysis. The Journal of Applied Behavioral Science, 39(3), 337-349.

[3] Borgatti, S. P., Jones, C., \& Everett, M. G. (1998). Network measures of social capital. Connections, 21(2), 27-36.

[4] Bozarth, C. C., Warsing, D. P., Flynn, B. B., \& Flynn, E. J. (2009). The impact of supply chain complexity on manufacturing plant performance. Journal of Operations Management, 27(1), 78-93.

[5] Choi, T. Y., \& Kim, Y. (2008). Structural embeddedness and supplier management: A network perspective*. Journal of Supply Chain Management, 44(4), 5-13.

[6] Choi, T. Y., \& Krause, D. R. (2006). The supply base and its complexity: Implications for transaction costs, risks, responsiveness, and innovation. Journal of Operations Management, 24(5), 637-652.

[7] Coleman, J. S. (1988). Social capital in the creation of human capital. American journal of sociology, S95-S120.

[8] Corteville, L., \& Sun, M. (2009). An interorganizational social network analysis of the michigan diabetes outreach networks. Michigan department of community health report.

[9] Ford, E. W., Wells, R., \& Bailey, B. (2004). Sustainable network advantages: a game theoretic approach to community-based health care coalitions. Health Care Management Review, 29(2), 159-169.

[10] Freeman, L. C. (1979). Centrality in social networks conceptual clarification. Social networks, 1(3), 215-239.

[11] Granovetter, M. (1985). Economic action and social structure: the problem of embeddedness. American journal of sociology, 481-510.

[12] Gulati, R. (1995). Does familiarity breed trust? The implications of repeated ties for contractual choice in alliances. Academy of management journal, 38(1), 85-112.

[13] Gulati, R., \& Gargiulo, M. (1999). Where do interorganizational networks come from? 1. American iournal of sociology, 104(5), 1439-1493.

[14] Gulati, R., \& Gargiulo, M. (1999). Where Do Interorganizational Networks Come From?. American Journal of Sociology, 104(5), 1398-438.

[15] Knoke, D., \& Kuklinski, J. H. (1982). Network analysis.

[16] Krackhardt, D. (1999). The ties that torture: Simmelian tie analysis in organizations. Research in the Sociology of Organizations, 16(1), 183-210.

[17] Mueller, N., Krauss, M., \& Luke, D. (2004). PEER REVIEWED: Interorganizational Relationships Within State Tobacco Control Networks: A Social Network Analysis. Preventing chronic disease, 1(4).

[18] Lusher, D. (2011). Masculinity, educational achievement and social status: a social network analysis. Gender and Education, 23(6), 655-675.

[19] Lusher, D., \& Robins, G. (2010). A social network analysis of hegemonic and other masculinities. The Journal of Men's Studies, 18(1), 22-44.

[20] Lusher, D., Robins, G., \& Kremer, P. (2010). The application of social network analysis to team sports. Measurement in physical education and exercise science, 14(4), 211-224.

[21] McEvily, B., Perrone, V., \& Zaheer, A. (2003). Trust as an organizing principle.Organization science, 14(1), 91-103.

[22] Zaheer, A., \& McEvily, B. (1999). Bridging ties: A source of firm heterogeneity in competitive capabilities. Strategic management journal, 20(12), 1133.

[23] Podolny, J. M., \& Page, K. L. (1998). Network forms of organization. Annual review of sociology, 5776.

[24] Powell, W. W. Neither market nor hierarchy: network forms of organization, 295-336. 1990. Greenwich, CT.

[25] Provan, K. G., \& Milward, H. B. (1991). Institutional-level norms and organizational involvement in a service-implementation network. Journal of Public Administration Research and Theory, 1(4), 391-418.

[26] Reagans, R., Zuckerman, E., \& McEvily, B. (2004). How to make the team: Social networks vs. demography as criteria for designing effective teams.Administrative Science Quarterly, 49(1), 101-133.

[27] Robins, G., Pattison, P., Kalish, Y., \& Lusher, D. (2007). An introduction to exponential random graph 
( $\mathrm{p}^{*}$ ) models for social networks. Social networks,29(2), 173-191.

[28] Robins, G., Pattison, P., \& Wang, P. (2009). Closure, connectivity and degree distributions: Exponential random graph ( $\left.\mathrm{p}^{*}\right)$ models for directed social networks. Social Networks, 31(2), 105-117.

[29] Scott, J. (1988). Social network analysis. Sociology, 22(1), 109-127.

[30] Snavely, K., \& Tracy, M. B. (2000). Collaboration among rural nonprofit organizations. Nonprofit Management and Leadership, 11(2), 145-165.

[31] Uzzi, B. (1997). Social structure and competition in interfirm networks: The paradox of embeddedness. Administrative science quarterly, 35-67.

[32] Wang, P., Robins, G., \& Pattison, P. (2006). PNet: A program for the simulation and estimation of exponential random graph models. University of Melbourne.

[33] Wang, P., Robins, G., \& Pattison, P. (2006). PNet: Program for the estimation and simulation of p* exponential random graph models, User Manual.Department of Psychology, University of Melbourne.

[34] Womack, JP (1990), Machine that changed the world, Scribner

[35] Wu, Z., Choi, T. Y., \& Rungtusanatham, M. J. (2010). Supplier-supplier relationships in buyersupplier-supplier triads: Implications for supplier performance. Journal of Operations Management, 28(2), 115-123. 